\title{
Psychiatric comorbidities among adolescents with and without anxiety disorders: a community study
}

\author{
Comorbidades psiquiátricas entre adolescentes com e sem \\ transtornos de ansiedade: um estudo da comunidade \\ Estácio Amaro da Silva Júnior', Camila Albuquerque de Brito Gomes²
}

\begin{abstract}
Objective: To evaluate, in a community sample of adolescents, the presence of comorbidities in different anxiety disorders. Methods: This is a cross-sectional study, initially composed of 2,457 adolescents, aged between 10-17 years old, from public schools of the area covered by the Basic Health Unit of a university hospital. We applied the Screen for Child Anxiety Related Emotional Disorders (SCARED) to assess for anxiety disorders. Then, 138 positive cases in the screening were assessed for mental disorders through the Schedule for Affective Disorder and Schizophrenia for School-Age Children - Present and Lifetime Version (K-SADS-PL). Results: Patients with anxiety disorders had more association with other anxiety disorders, as well as depression, and enuresis. The most common comorbidity described in our study was between generalized anxiety disorder and separation anxiety disorder ( $O R=4.21,95 \%$ $\mathrm{Cl} 1.88,9.58)$. Significant association was observed between other disorders such as enuresis and separation anxiety disorder $(\mathrm{OR}=3.81,95 \% \mathrm{Cl} 1.16,12.49)$, as well as depression and generalized anxiety disorder ( $\mathrm{OR}=3.40 ; 95 \% \mathrm{Cl} 1.52,7.61)$. Conclusion: Our study showed a relevant presence of comorbidities adolescents with anxiety disorders, selected from a community sample, especially regarding other anxiety disorders. Nevertheless, further studies are needed to confirm our findings.
\end{abstract}

\section{Keywords}

Child psychiatry, anxiety disorders, psychiatric comorbidities, depression, enuresis.

\section{RESUMO}

Objetivo: Avaliar, em uma amostra comunitária de adolescentes, a presença de comorbidades nos distintos transtornos de ansiedade. Métodos: Estudo transversal, composto por 2.457 adolescentes de 10 a 17 anos, provenientes das escolas públicas da área de abrangência da Unidade Básica de Saúde de um hospital universitário, que foram avaliados para transtornos de ansiedade, por meio da Screen for Child Anxiety Related Emotional Disorders (SCARED). Desses, 138 casos foram positivos pela SCARED e avaliados para transtornos mentais, por meio do Schedule for Affective Disorders and Schizophrenia for School-Age Children-Present and Lifetime Version (K-SADS-PL). Resultados: Pacientes com transtornos de ansiedade apresentavam mais comorbidades com outros transtornos de ansiedade, bem como com depressão e enurese. As comorbidades mais frequentes descritas em nosso estudo foram transtorno de ansiedade generalizada e transtorno de ansiedade de separação (OR =4,21; IC 95\% 1,88; 9,58). Foi observada associação significativa com outros transtornos, tais como enurese com

1 Federal University of Rio Grande do Sul (UFRGS), Anxiety Disorders Program for Children and Adolescents. 2 Faculdade de Medicina Nova Esperança (Famene).

Address for correspondence: Estácio Amaro da Silva Júnior Av. Flávio Ribeiro Coutinho, 205, sala 708 58037-000 - João Pessoa, PB, Brazil E-mail: estacioamaro@yahoo.com.br 


\section{Palavras-chave}

Psiquiatria infantil, transtornos de ansiedade, comorbidades psiquiátricas, depressão, enurese. transtorno de ansiedade de separação (OR = 3,81; IC 95\% 1,16; 12,49) e depressão com transtorno de ansiedade generalizada $(\mathrm{OR}=3,40 ; \mathrm{IC} 95 \%$ 1,52; 7,61). Conclusão: $\mathrm{A}$ presença de comorbidades em adolescentes com transtornos de ansiedade selecionados de uma amostra comunitária foi frequente. Estudos complementares para confirmar nossos resultados são necessários.

\section{INTRODUCTION}

Anxiety disorders comprise a heterogeneous group of illnesses that have in common heightened and excessive levels of fear, which often leads to functional impairment and adverse physical symptoms. Include generalized anxiety disorder, panic disorder, social anxiety disorder, specific phobia, separation anxiety disorder and now reorganized for DSM-5 as separate categories post-traumatic stress disorder and obsessive-compulsive disorder ${ }^{1,2}$.

Anxiety disorders composes the most common group of mental illnesses that affects adolescents ${ }^{3,4}$, with a cumulative prevalence of $10 \%$ by the age of 16 years old ${ }^{5}$, and a lifetime prevalence of $29 \%$. When impairment in daily functioning is considered, prevalence rates of 5\% to $10 \%$ are reported ${ }^{7}$. A cohort study, from a national sample of 755 children and adolescents referred to a psychiatric service, in Denmark, between 2004 and 2007, describes a prevalence of anxiety disorder of $5.7 \%$. The presence of anxiety disorder is associated with low self-esteem, difficulties in relationships with peers and family, difficulties in the development at school, and also with disruptive behavior disorders 9 .

These anxiety disorders present high rates of comorbidity among them, and with depression ${ }^{10,11}$. Studies with community samples have found rates of comorbidity among anxiety disorders and other disorders raging from 14\% to 39\%12,13. The common presentation is anxiety preceding depression, and thus, anxiety is considered one of the most common mental disorders in childhood ${ }^{14,15}$, while depression rates increase significantly in adolescence ${ }^{16,17}$.

It is also important to mention that studies reveal that anxiety causing events appear to be the main reason for enuresis in adolescence ${ }^{17}$. Enuresis after the age of 10 years may be associated with a poor self-concept or other psychological problems. In addition, bed-wetting after the age of 10 years is associated with small but detectable increases in risk of conduct problem, attention deficit behaviors, and anxiety/ withdrawal in early adolescence ${ }^{18,19}$.

There is a lack of studies using community samples of children and adolescents focused on studying the presence and patterns of different comorbidities. Although many studies investigate comorbidities in childhood and adolescence, only a few evaluate elimination disorders. In addition, even though the excretion disorders (enuresis and encopresis) are classified in the Diagnostic and Statistical Manual of Mental Disorders, Fifth Edition (DSM-5) as well as in the
International Classification of Diseases (ICD-10), they are not found to be a usual subject of study in Psychiatry researches².

Thinking about the next edition of the DSM, it is important to investigate comorbidities in order to better understand the clinical presentation of anxiety disorders. This study focuses on generalized anxiety disorder, social anxiety disorder, specific phobia, separation anxiety disorder and panic disorder. It excludes the obsessive-compulsive disorder and posttraumatic stress disorder because they have specific characteristics that differentiate them from others, as indicated by the DSM- 5 as a separated category of disorder ${ }^{2}$.

The intent of this study is to evaluate the presence of comorbidities in a community sample of adolescents diagnosed with anxiety disorder.

\section{METHODS}

\section{Sample selection}

A total of 2,457 students (adolescents), aged from 10 to 17 years old, enrolled in six public schools belonging to the areas assisted by the primary care unit of a university hospital Hospital de Clínicas de Porto Alegre (HCPA) - participated in the community study. Most of the adolescents resided with their biological mother, and siblings. The majority did not have the paternal figure present in their homes, and a smaller portion had their grandparents residing together with their mother, and siblings, in the same house. They were assessed through the SCARED, a questionnaire designed to screen for the presence of DSM-IV anxiety disorders in children and adolescents aged 9-18 years old ${ }^{20}$.

All subjects above the $75^{\text {th }}$ percentile $(n=160)$ in the screening scale (SCARED), and their parents, were invited to a semi-structured interview (K-SADS-PL) ${ }^{21}$, performed by six interviewers (four child psychiatrists and two Psychiatry residents with inter-rater reliability resulting in Kappa $=0.93$ for the anxiety disorders module); 138 adolescents evaluated had an anxiety disorder (86.25\%).

The SCARED was applied at school, in the classroom. School directors and teachers granted authorization prior to the process, and the K-SADS-PL was performed in a hospital room, lasting on average two and a half hours. When cases of anxiety were detected, the adolescents were referred to psychologists, members of our research group, who provided a brief behavioral therapy intervention. In addition, child psychiatrists evaluated the adolescents at the beginning, 
middle and end of each therapeutic group, and outpatient care was indicated when needed.

The contact with the subjects to undergo clinical evaluation was made by phone, by the interviewers themselves. Students who did not have a telephone, or who did not know their telephone numbers, were excluded from the study. A loss of contact was defined after 5 calls, in different days, or in different periods of the day (at least one morning, one afternoon, one night and one day of weekend). Possible cases ( $n=160)$, according to SCARED, and their parents were evaluated. Adolescents diagnosed with social anxiety disorder, generalized anxiety disorder, separation anxiety disorder or panic disorder, according to the K-SADS-PL, were selected. Enuresis was diagnosed by the diagnostic criteria of DSMIV-TR, and there were no reported cases of anatomical abnormalities or neurological disability or chronic illness. The refusal to participate is described in figure 1.

After complete description of the study to the subjects, all parents provided written informed consent for participating in the study, and the adolescents provided written assent. This study was approved by the Research and Ethics Committee of HCPA (08-017).

\section{Statistical analysis}

The categorical variables were described as numbers and percentages (\%). Also, continuous variables were expressed as mean and standard deviation (SD). We considered having

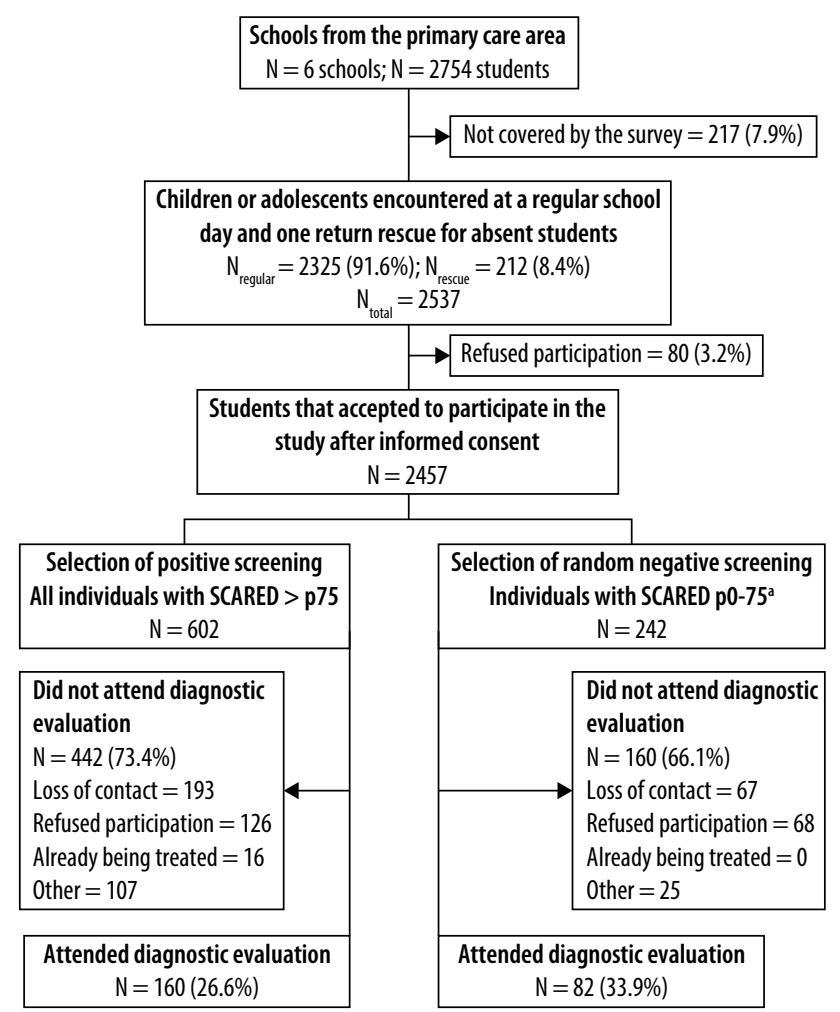

a To each percentile group was attributed the same number of subjects.

Figure 1. Flowchart showing each step of sample selection. or not having anxiety disorder as the outcome variable. Moreover, Pearson chi-square or the Fisher exact test was used to verify the association among categorical variables, and student $t$ test was used to compare the average age among the groups. In addition, we used a logistic regression model to estimate the odds ratio (OR) for each comorbidity on the outcomes, adjusted for age, sex and social class. IQ below 70 was considered an exclusion criterion.

We established a level of significance of $5 \%$, as well as a confidence interval (Cl) of 95\% was used in all tests. The analyses were performed through the SPSS (Statistical Package for Social Science) version 18.0.

\section{RESULTS}

The total number of adolescents with anxiety disorders assessed by the K-SADS- PL was 138. The total sample comprised $68.1 \%$ females $(n=94)$ and the mean age in years was 13.4 ( $S D=2.38$ ). Most of the sample was composed by Caucasians ( $n=95 ; 68.8 \%)$, and by individuals with low socioeconomic status ( $n=85 ; 61.5 \%$ ).

Considering gender, significant associations were found between Attention Deficit Hyperactivity Disorder and male gender, as well as between specific phobia and the female gender. Moreover, anxiety in lifetime, as a group, were present more frequently in females (Table 1).

From 138 cases of anxiety disorders (generalized anxiety disorder, panic disorder, social anxiety disorder, and separa-

Table 1. Relation between gender and psychiatric disorders

\begin{tabular}{|c|c|c|c|c|c|c|c|}
\hline \multirow{3}{*}{ Disorder } & & & \multicolumn{4}{|c|}{ Gender } & \multirow[b]{3}{*}{$p$} \\
\hline & \multicolumn{2}{|c|}{$\begin{array}{l}\text { Total } \\
(\mathrm{N}=242)\end{array}$} & \multicolumn{2}{|c|}{$\begin{array}{c}\text { Male } \\
(\mathrm{N}=77 ; 31.8 \%)\end{array}$} & \multicolumn{2}{|c|}{$\begin{array}{c}\text { Female } \\
(\mathrm{N}=165 ; 68.1 \%)\end{array}$} & \\
\hline & $\mathrm{N}$ & $\%$ & N & $\%$ & N & $\%$ & \\
\hline Enuresis & 21 & 8.7 & 10 & 13.0 & 11 & 6.7 & $0.104^{* *}$ \\
\hline Encopresis & 3 & 1.2 & 2 & 2.6 & 1 & 0.6 & $0.238^{*}$ \\
\hline$A D H D^{\mathrm{a}}$ & 63 & 26 & 27 & 35.1 & 36 & 21.8 & $0.029 * *$ \\
\hline $0 D D^{b}$ & 48 & 19.8 & 14 & 18.2 & 24 & 14.5 & $0.469^{* *}$ \\
\hline Panic in life & 9 & 3.7 & 3 & 3.9 & 6 & 3.6 & $1.000^{*}$ \\
\hline $\begin{array}{l}\text { Specific phobia } \\
\text { in life }\end{array}$ & 84 & 34.7 & 19 & 24.7 & 65 & 39.4 & $0.025^{* *}$ \\
\hline Tics in life & 17 & 7 & 9 & 11.7 & 8 & 4.9 & $0.054^{* *}$ \\
\hline Depression & 46 & 19 & 11 & 14.3 & 35 & 21.6 & $0.180^{* *}$ \\
\hline $\begin{array}{l}\text { Separation } \\
\text { anxiety in life }\end{array}$ & 49 & 20.2 & 14 & 18.2 & 35 & 21.2 & $0.585^{* *}$ \\
\hline $\begin{array}{l}\text { Generalized } \\
\text { anxiety in life }\end{array}$ & 95 & 39.3 & 25 & 32.5 & 70 & 42.4 & $0.140^{* *}$ \\
\hline $\begin{array}{l}\text { Social anxiety } \\
\text { in life }\end{array}$ & 57 & 23.5 & 15 & 19.5 & 42 & 25.5 & $0.308^{* *}$ \\
\hline Anxiety in life & 138 & 57 & 36 & 46.8 & 102 & 61.8 & $0.027^{*}$ \\
\hline
\end{tabular}

ADHD: attention deficit hyperactivity disorder; ${ }^{b} \mathrm{ODD}$ : oppositional defiant disorder; ${ }^{*} P$ value for the Fisher exact test; ${ }^{* *} P$ value for the Pearson qui-squared test. Data expressed as n. $P<0.05$ is considered statiscally significant. 
tion anxiety disorder) identified in the sample, $68.8 \%$ were diagnosed with generalized anxiety disorder $(n=95), 41.3 \%$ with social anxiety disorder $(n=57), 35.5 \%$ with separation anxiety disorder $(n=49)$, and $6.5 \%$ with panic disorder ( $n=$ 09). Considering the number of comorbidities, $58.2 \%$ of the cases had only one anxiety disorder, $30.6 \%$ had two anxiety disorders and $10.4 \%$ had three or four anxiety disorders during lifetime.

Comorbidities associated with anxiety disorders are very common, especially among them. The most frequently association found in our study was between generalized anxiety disorder and separation anxiety disorder $(\mathrm{OR}=4.21,95 \% \mathrm{Cl}$ $=1.88-9.58$ ). We observed that patients with anxiety disorder have higher rates of enuresis and separation anxiety disorder $(\mathrm{OR}=3.81,95 \% \mathrm{Cl}=1.16-12.49)$, depression and generalized anxiety disorder $(\mathrm{OR}=3.40,95 \% \mathrm{Cl}=1.52-7.61)$, and depression and social anxiety disorder $(\mathrm{OR}=2.57,95 \% \mathrm{Cl}=1.14$ 5.79). According to our study, patients with anxiety disorder had an increased risk of having another anxiety disorder as depicted on table 2. Individuals who have enuresis are 3.81 times more likely to have separation anxiety disorder than those without this comorbidity $(\mathrm{OR}=3.81,95 \% \mathrm{Cl} 1.16-12.49$, $p=0.001$.

\section{DISCUSSION}

Many authors reported that anxiety disorders could be studied as a unique group, once they have similar clinical presentation, etiology, outcome, as well as intervention ${ }^{22}$. Moreover, the high frequency of coexistence among them, described by the present study, is in agreement with what has been discussed in the literature ${ }^{12,23,24}$.

Our study suggests that the presence of one anxiety disorder increases the risk of having another anxiety disorder or any other axis I disorder, as described in previous studies $9,11,12,23$. For instance, it demonstrated that adolescents with enuresis, specific phobia, generalized anxiety disorder, and tic disorders are more likely to have separation anxiety disorder. Furthermore, those with social anxiety disorder, specific phobia, and depression are more likely to present with generalized anxiety disorder, as well as those with specific phobia, generalized anxiety disorder and depression are more likely to have social anxiety disorder. We also found a high association between generalized anxiety disorder and depression, which adds another point to the discussion of the validity of these conditions as distinct diagnosis or as part of the same nosological classification ${ }^{25,26}$.

According to the study of Verduin and Kendall127, which assessed the comorbidities in children and adolescents between the ages of 8 and 13 years, with primary diagnoses of generalized anxiety disorder, separation anxiety disorder or social anxiety disorder, functional enuresis was more common in those with separation anxiety disorder. In agreement with this finding, we described a higher probability of individuals presenting enuresis to have separation anxiety disorder than those without this comorbidity. We also consider the hypothesis that enuresis could be a clinical manifestation of separation anxiety disorder, and not only a comorbid condition.

Additionally, we observed a higher frequency of anxiety disorders among the female gender group, which is in agreement with one review that assessed the prevalence of psychiatric disorders among women ${ }^{22}$. However, this finding is not entirely consistent, once there are studies that failed to demonstrate significant gender differences in the prevalence of anxiety disorders ${ }^{13,28}$.

Parents of children and adolescents suffering from separation anxiety disorder exhibited a significantly higher prevalence of psychopathology, mainly anxiety disorders and

Table 2. Odds ratio adjusted for age, gender and social class, and estimated for the outcomes of separation anxiety disorder, generalized anxiety disorder, and social anxiety disorder

\begin{tabular}{|c|c|c|c|c|c|c|c|c|c|}
\hline & \multicolumn{3}{|c|}{ Separation anxiety disorder } & \multicolumn{3}{|c|}{ Generalized anxiety disorder } & \multicolumn{3}{|c|}{ Social anxiety disorder } \\
\hline & OR & $95 \% \mathrm{Cl}$ & $p$ & OR & $95 \% \mathrm{Cl}$ & $p$ & OR & $95 \% \mathrm{Cl}$ & $p$ \\
\hline Enuresis & 3.81 & $1.16,12.49$ & 0.027 & 1.57 & $0.50,4.96$ & 0.445 & 0.60 & $0.13,2.88$ & 0.525 \\
\hline Encopresis & 4.39 & $0.25,76.90$ & 0.311 & 0.00 & 0.00 & 0.999 & 0.00 & 0.00 & 0.999 \\
\hline$A D H D^{a}$ & 0.58 & $0.22,1.52$ & 0.272 & 0.87 & $0.44,1.72$ & 0.686 & 1.39 & $0.66,2.92$ & 0.391 \\
\hline$O D D^{b}$ & 1.05 & $0.36,3.06$ & 0.925 & 0.73 & $0.31,1.67$ & 0.450 & 0.66 & $0.25,1.76$ & 0.406 \\
\hline Panic & 2.45 & $0.42,14.43$ & 0.323 & 3.68 & $0.66,20.58$ & 0.138 & 0.99 & $0.18,5.59$ & 0.993 \\
\hline $\operatorname{SAD}^{c}$ & 1.76 & $0.76,4.05$ & 0.187 & 2.87 & $1.44,5.71$ & 0.003 & - & - & - \\
\hline Specific Phobia & 3.33 & $1.50,7.38$ & 0.003 & 2.81 & $1.49,5.28$ & 0.001 & 3.38 & $1.68,6.77$ & 0.001 \\
\hline$G A D^{d}$ & 4.25 & $1.88,9.58$ & $<0.001$ & - & - & - & 2.87 & $1.44,5.72$ & 0.003 \\
\hline Tic & 4.10 & $1.23,13.75$ & 0.022 & 1.74 & $0.54,5.59$ & 0.352 & 2.47 & $0.74,8.30$ & 0.142 \\
\hline Depression & 2.45 & $0.94,6.42$ & 0.068 & 3.40 & $1.52,7.61$ & 0.003 & 2.57 & $1.14,5.79$ & 0.023 \\
\hline
\end{tabular}

${ }^{\mathrm{a}} \mathrm{ADHD}$ : attention deficit hyperactivity disorder; ${ }^{\mathrm{b}} \mathrm{ODD}$ : oppositional defiant disorder; ' $\mathrm{SAD}$ : social anxiety disorder; ${ }^{\mathrm{G}} \mathrm{GDD}$ : generalized anxiety disorder; $P<0.05$ is considered statiscally significant. 
mood disorders. Mothers predominantly suffered from social phobia and specific phobia. Fathers most frequently suffered from obsessive-compulsive disorder and social phobia ${ }^{29}$.

Nevertheless, our study had some limitations that should be acknowledged. The small sample size was due to many refusals to participate in this study. As the participants came from a community sample, subjects were not looking for treatment, and the participation in the study required a hospital visit demanding time and costs. Despite this, there was a clear association of certain comorbidities with the hypotheses investigated. Also, the confidence intervals are long, which shows low accuracy in the estimation of odds ratios. We planned to minimize our confounding factors by selecting a school sample from the same social class and neighborhood.

\section{CONCLUSIONS}

To summarize, we found a high prevalence of comorbidities and association of enuresis with separation anxiety disorder in this study in a community sample. The presence of anxiety disorders is frequent in adolescents and these conditions are responsible for a strong impact in the development of these individuals ${ }^{1,8}$.

Anxiety disorders when present in youth increase the risk of suicide attempts, as well as the risk of secondary mood and anxiety disorders, and are associated with significant morbidity and mortality ${ }^{30}$.

\section{INDIVIDUAL CONTRIBUTIONS}

Estácio Amaro da Silva Júnior - Was involved in conception and design of the study, as well as coordinated and supervised data collection, critically reviewed the manuscript, and approved the final manuscript as submitted.

Camila Albuquerque de Brito Gomes - Carried out the initial analyses, drafted the manuscript, reviewed and revised the manuscript, and approved the final manuscript as submitted.

\section{CONFLICTS OF INTEREST}

The authors have no conflicts of interest to disclose.

\section{FINANCIAL DISCLOSURE}

The authors have no financial relationships relevant to this article to disclose.

\section{ACKNOWLEDGMENTS}

Funding source: All phases of this study were supported by Conselho Nacional de Desenvolvimento Científico e Tecnológico (CNPq) and by Fundo de Incentivo à Pesquisa e Eventos do Hospital de Clínicas de Porto Alegre (FIPE-HCPA).

\section{REFERENCES}

1. Helton SG, Lohoff FW. Serotonin pathway polymorphisms and the treatment of major depressive disorder and anxiety disorders. Pharmacogenomics. 2015;16(5):541-53.

2. American Psychiatric Association. Diagnostic and statistical manual of mental disorders. 5th ed. Arlington, VA: American Psychiatric Publishing; 2013.

3. Rapee RM, Schniering CA, Hudson JL. Anxiety disorders during childhood and adolescence: origins and treatment. Annu Rev Clin Psychol. 2009;5:311-41.

4. Ramtekkar U, Ivannenko A. Sleep in children with psychitric disorders. Sem Pediatr Neurol. 2015;22:148-55.

5. Costello EJ, Mustillo S, Erkanli A, Keeler G, Angold A. Prevalence and development of psychiatric disorders in childhood and adolescence. Arch Gen Psychiatry. 2003;60(8):837-44.

6. Kessler RC, Berglund P, Demler 0 , Jin R, Merikangas KR, Walters EE. Lifetime prevalence and age-of-onset distributions of DSM-IV disorders in the National Comorbidity Survey Replication. Arch Gen Psychiatry. 2005;62(6):593-602.

7. Bodden DH, Dirksen CD, Bögels SM. Societal burden of clinically anxious youth referred for treatment: a cost-of-illness study. J Abnorm Child Psychol. 2008;36:487-97.

8. Esbjørn BH, Hoeyer M, Dyrborg J, Leth I, Kendall PC. Prevalence and co-morbidity among anxiety disorders in a national cohort of psychiatrically referred children and adolescents. J Anxiety Disord. 2010;24(8):866-72.

9. Ezpeleta L, Keeler G, Erkanli A, Costello EJ, Angold A. Epidemiology of psychiatric disability in childhood and adolescence. J Child Psychol Psychiatry. 2001;42(7):901-14.

10. Axelson DA, Birmaher B. Relation between anxiety and depressive disorders in childhood and adolescence. Depress Anxiety. 2001;14(2):67-78.

11. Beidel DC, Turner SM, Morris TL. Psychopathology of childhood social phobia. J Am Acad Child Adolesc Psychiatry. 1999;38(6):643-50.

12. McGee R, Feehan M, Williams S, Anderson J. DSM-III disorders from age 11 to age 15 years. J Am Acad Child Adolesc Psychiatry. 1992;31(1):50-9.

13. Kashani JH, Orvaschel H. A community study of anxiety in children and adolescents. Am J Psychiatry. 1990;147(3):313-8.

14. Canino G, Shrout PE, Rubio-Stipec M, Bird HR, Bravo M, Ramirez R, et al. The DSM-IV rates of child and adolescent disorders in Puerto Rico: prevalence, correlates, service use, and the effects of impairment. Arch Gen Psychiatry. 2004;61(1):85-93.

15. Breton JJ, Bergeron L, Valla JP, Berthiaume C, Gaudet N, Lambert J, et al. Quebec child mental health survey: prevalence of DSM-III-R mental health disorders. J Child Psychol Psychiatry. 1999;40(3):375-84.

16. Roza SJ, Hofstra MB, van der Ende J, Verhulst FC. Stable prediction of mood and anxiety disorders based on behavioral and emotional problems in childhood: a 14-year follow-up during childhood, adolescence, and young adulthood. Am J Psychiatry. 2003;160(12):2116-21.

17. Hankin BL, Abramson LY, Moffitt TE, Silva PA, McGee R, Angell KE. Development of depression from preadolescence to young adulthood: emerging gender differences in a 10-year longitudinal study. J Abnorm Psychol. 1998;107(1):128-40.

18. Ramam S, Venkata RR, Santhoshi LG, Jyothi B, Divya BD, Vidya BK. A study on pevalence of nocturnal enuresis among rural pediatric and adolescent population. Int J Pharm Clin Res. 2015;7:92-5.

19. Elbahnasawy HT, Elnagar MA. Psychological impact of nocturnal enuresis in self-esteem of school children. Am J Nurs Res. 2015;3:14-20.

20. Birmaher B, Brent DA, Chiappetta L, Bridge J, Monga S, Baugher M. Psychometric properties of the Screen for Child Anxiety Related Emotional Disorders (SCARED): a replication study. J Am Acad Child Adolesc Psychiatry. 1999;38(10):1230-6.

21. Kaufman J, Birmaher B, Brent D, Rao U, Flynn C, Moreci P, et al. Schedule for Affective Disorders and Schizophrenia for School-Age Children-Present and Lifetime Version 
(K-SADS-PL): initial reliability and validity data. J Am Acad Child Adolesc Psychiatry. 1997;36(7):980-8

22. Andrade LHSG, Viana MC, Silveira CM. Epidemiology of women's psychiatric disorders. Rev Psiquiatr Clín. 2006;33:43-54.

23. Benjamin RS, Costello EJ, Warren M. Anxiety disorders in a pediatric sample. J Anxiety Disord. 1990:4:293-316.

24. Last CG, Strauss CC, Francis G. Comorbidity among childhood anxiety disorders. J Nerv Ment Dis. 1987;175(12):726-30

25. Krueger RF. The structure of common mental disorders. Arch Gen Psychiatry. 1999:56(10):921-6.

26. Wittchen HU, Carter RM, Pfister H, Montgomery SA, Kessler RC. Disabilities and quality of life in pure and comorbid generalized anxiety disorder and major depression in a national survey. Int Clin Psychopharmacol. 2000;15(6):319-28.
27. Verduin TL, Kendall PC. Differential occurrence of comorbidity within childhood anxiety disorders. J Clin Child Adolesc Psychol. 2003;32(2):290-5.

28. Ford T, Goodman R, Meltzer H. The British Child and Adolescent Mental Health Survey 1999: the prevalence of DSM-IV disorders. J Am Acad Child Adolesc Psychiatry. 2003:42(10):1203-11.

29. Sackl-Pammer P, Popow C, Schuch B, Aigner M, Friedrich M, Huemer J. Psychopathology among parents of children and adolescents with separation anxiety disorder. Neuropsychiatr. 2015;29(1):23-8

30. Strawn JR, Welge JA, Wehry AM, Keeshin B, Rynn MA. Efficacy and tolerability of antidepressants in pediatric anxiety disorders: a systematic review and meta-analysis. Depress Anxiety. 2015;32(3):149-57. 